disclosure requirements, an opportunity now exists to focus the SEC on using biotech-specific guidelines to specify those disclosures that are relevant to the biotech companies from a reasonable investor's point of view and eliminate the disclosure that has grown over the years and is no longer relevant.

Biotech companies would also benefit if the SEC acknowledged that an investor in the biotech sector should be presumed to have some knowledge of the regulatory factors affecting biotech business, such as the US Food and Drug Administration approval process, and a rudimentary understanding of patents whose ownership is a vital component of the value of a drug and reflected in the market value of a biotech company without marketed products. The SEC also could revise its rules to recognize that institutional investors and not individual investors contribute actively to the price-setting mechanism of the public capital markets. Thus, the regulatory framework should take into account that any investor in a specialized field like biotech has to take the responsibility for understanding the industry and some of the fundamental science necessary to appreciate a particular company's business. Disclosure has become voluminous as too much emphasis has been placed on the biotech company having to explain industry basics to presumably uninformed investors.

The acceptance of the premise that an investor has a basic level of familiarity with an industry and its business fundamentals might contribute to the SEC ameliorating the extent of risk factor disclosures currently provided to investors, which can run to 20 or more pages. Comments on company filings by the SEC staff are only one source of pressure to include extensive risk factors. The major driver of the expanded lists of risk factors has been the perceived protection they provide against future securities law litigation. The "bespeaks-caution doctrine" adopted by the US courts and "safe harbors" for forwardlooking statements support the idea that a company can protect itself by not skimping on risk factors. That results in the inclusion of risk factor disclosures that should be obvious to even a reasonably educated investor. The SEC encouraged inclusion of fewer risk factors as part of its plain-English initiative in the late 1990s. Even so, companies and their lawyers resisted that pressure without some assurance from the SEC that they would not be giving up what has been considered to be liability protection. Similarly, if disclosure reform results in companies not being required to disclose information that had been included as a matter of course in the past, the SEC will need to protect companies that avail themselves of reduced disclosure enacted by the SEC.

Although the SEC staff report mandated by the JOBS Act calls for a comprehensive review of the disclosure requirements rather than incremental steps to ease the disclosure burden, this should not preclude the SEC from making immediate changes in the right direction. Recently, SEC staff has taken some minor steps in this regard by reducing the disclosures it has been requiring in IPO prospectuses on the valuation methods the company has used to determine the exercise prices of stock options granted preceding the IPO. Over the years, what began as SEC staff comment letters requesting details to ensure appropriate accounting for stock options (and related so-called 'cheap stock' issues) grew into several pages of disclosure in IPO prospectuses detailing the company's valuation of its own stock for optionsgranting purposes.

Along with the opportunity it presents, disclosure reform poses risks to the biotech industry. When regulators make changes, even if focused primarily on reducing disclosure overload, they are likely to include increased requirements in certain areas. One area of potential pressure could be toward faster disclosure. Other countries have continuous disclosure regimes, whereas the underlying premise of US securities laws is that, absent a duty to disclose, no disclosure is required. The periodic disclosure requirements-such as Form 10-Ks, Form 10-Qs and proxy statements, as well as the Form 8-K mandating current reporting obligations of material events-impose limits on that premise, while still providing meaningful protection to companies in many circumstances. Weakening that approach or mandating that companies report new developments more quickly than currently required would place additional burdens on companies to increase staff for this disclosure framework and could result in liability in more situations than is already the case.

Many factors have contributed to our current state of US public company disclosure. The SEC's current efforts to consider disclosure reform that could reduce the burdens of that disclosure are welcome. Biotech companies and $\mathrm{BIO}$ have an opportunity to contribute to the success of that effort and to help shape the reforms in ways that particularly benefit biotech companies and their investors. This is an opportunity to make their voices heard and help shape their disclosure destiny.

COMPETING FINANCIAL INTERESTS

The authors declare no competing financial interests.

\section{Robert Evans III \& Mark Kessel}

Shearman \& Sterling LLP, New York, New York, USA. e-mail:revans@shearman.comor mark.kessel@shearman.com

\title{
iGEM 2.0—refoundations for engineering biology
}

\section{To the Editor:}

The international Genetically Engineered Machine (iGEM) student competition is both a workbench and a showcase for synthetic biology. The competition is based on a simple idea: synthetic biology engineering principles of standardization, abstraction and modularity can be applied to biotech to make engineering new functions in life systems less intimidating, more accessible and more predictable. This year, iGEM will have been running for a decade, and the organization will celebrate the event with a 'giant jamboree' involving as many as 300 teams. The competition has reached a peak in terms of media impact (with a considerable number of Internet searches and a clear seasonal search pattern fitting the competition calendar (http://www.google.es/ trends/explore\# $\mathrm{q}=$ igem, accessed 17 December 2013), attendance and expectations. As former participants in iGEM (C.V. was a student attendee for three years and M.P. was a team supervisor and judge for six years), we have conducted an analysis of iGEM projects presented over the past 10 years. Our analysis reveals several challenges that the competition must face if it is to remain a flagship of synthetic biology.

iGEM takes place in a pedagogic setting and within a time frame of less than 1 year, in such a way that even undergraduate students without prior training in biology, but with reasonable technical and theoretical support, can participate ${ }^{1}$. It has been described as a test bed of synthetic biology projects; as 
Figure 1 iGEM attendee analysis. (a) Number of teams attending iGEM by region. (b) Regional origin of attendees. Shading indicates the cumulative number of teams representing each region since 2004 . The distribution of awards is represented by circles, whose size is proportional to the number of finalist teams representing each country (smallest circles represent one finalist team, whereas the biggest one represents 14 finalist teams since 2006). For European teams, awards are represented by country (green circles) as well as for the whole continent (orange circle).

a

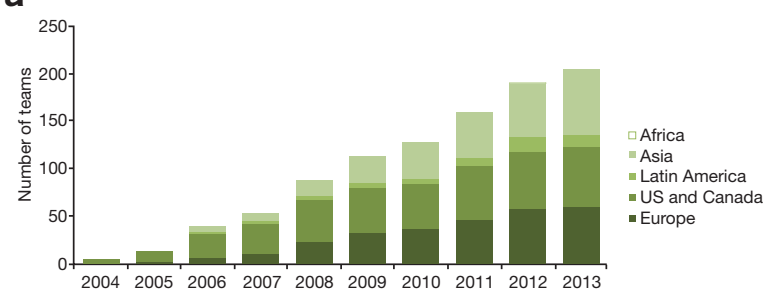

b

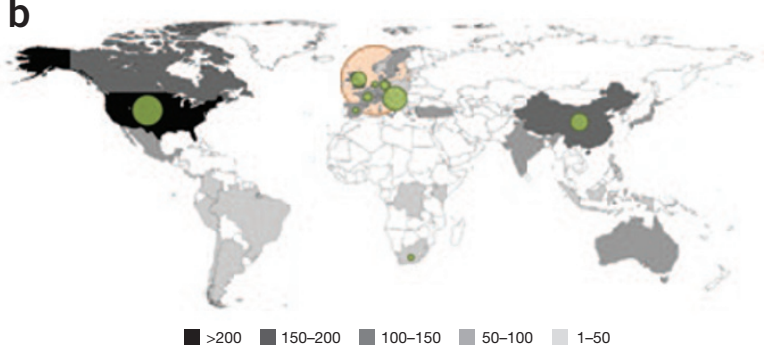

an example of engineering ingenuity ${ }^{2}$; as a framework for increasing interest in 'human practices' (the term used in iGEM referring to ethical, legal and social implications (ELSI)) approaches, such as biosecurity and biosafety ${ }^{3}$ and intellectual property ${ }^{4}$; and as a challenge providing leadership to the field ${ }^{5}$. iGEM seeks to not only educate young students in synthetic biology but also foster other personal abilities, such as self-confidence, creativity and effort. Multicultural and interdisciplinary exchange of knowledge, teamwork, networking and information sharing via public wikis are also part of the additional values of the iGEM experience.

The peak of the iGEM competition is the jamboree, where the teams present their synthetic biology projects conducted during the summer. Since 2011, the competition has been organized in regional jamborees that take place in October, and only a percentage (around one-third) of the teams go to the world championship, which is held the first week of November at the Massachusetts Institute of Technology (MIT) in Cambridge, Massachusetts.

Over the past decade, participation in the competition has expanded from an early group of US projects to $>200$ teams distributed worldwide (Fig. 1). Even so, the geographical distribution of iGEM participants remains biased toward North America, Eastern Asia and Europe. Every year each of these regions account for around $25 \%$ of the participating teams; however, groups from Latin America have been more involved in recent years (Fig. 1a). In terms of awards, Europe has been the most successful continent (Fig. 1b); indeed, there have been three competitions in which all the finalists were of European origin. One team, from Ljubljana, Slovenia, has reached the finalists pool (comprising three teams) and been awarded the grand prize five and three times, respectively.

In terms of judges, geographical distribution is predominantly local in the regional jamborees (i.e., judges come from where the regional jamboree is based) and international in the world phase. Even so, the diversity is lower among judges than among teams in the world jamboree; overall, there is a strong geographic bias in favor of US and European judges over Asian ones (see http:// igem.org/Judge_List and http://2013.igem. org/Judging/Transparency_at_iGEM).

In terms of funding, an average team attending the regional phase (ten students and two advisors) spends a minimum of $\$ 10,000$ just for team and individual fees, travel and lodging (this does not include the additional fees when teams advance to the world championship). Added to this is the cost of the rather expensive materials and technologies used to perform often ambitious wet lab experiments in iGEM (such costs can range from thousands to tens of thousands of dollars, depending on the project). In the absence of publicly available data, we estimate (very roughly) that the average cost per team is around $\$ 20,000-50,000$ per year, suggesting that the cost for all participants in the 2013 competition overall was approximately $\$ 4$ million-10 million.

Although the total price tag for each year's iGEM is similar to that of a medium-to-large cooperative scientific project, which would be expected to yield important scientific publications and/or patents, it is important to stress that iGEM is an educational program.
As such, its success should not be measured in terms of scientific publications or patents. In fact, each iGEM competition typically yields very few scientific publications or intellectual property and, to the best of our knowledge, fewer than half of the finalist projects have been published so far. The rate of published iGEM projects has not risen in line with the maturity of the competition (Table 1).

A set of specialized volunteer judges choose medal and award winners and select which teams will advance from regional competitions to the world championship. In the last world jamboree, 52 judges were in charge of assessing the performance of 146 teams. The majority of judges (76.9\%) came from academia (many of which were also team instructors); $9.6 \%$ originated from government departments; $5.8 \%$ were from companies; and the remaining $7.7 \%$ were from the committee (iGEM organizers; see http://igem.org/Judge_List).

Whereas in regional competitions judges consider a team's overall project on the wiki, presentation, modeling of the problem, submission and use of BioBrick standards, in the world championship only four aspects of the project are assessed (overall project, wiki, presentation and modeling). Each judge casts votes that are converted into a numerical score in an online-based rubric. There is a double award system. First, medals (gold, silver and bronze) are awarded on completion of a list of requisites, including the construction of new BioBrick parts, the submission of these parts to the Registry of Standard Biological Parts (http://parts. igem.org/Main_Page) and the assessment of the project in terms of safety and bioethics. Second, prizes are awarded by judges to the winner, first runner-up and second runner-up (http://2013.igem.org/Judging/ Awards). Only about one-third of the teams advance to the world championship at MIT, and this rate might become even more competitive in the coming years if attendance continues to rise.

The iGEM competition and the Registry of Standard Biological Parts are two branches of the same tree. In fact, one requisite to earn a medal is to submit at least one biological part, either natural or engineered, to the registry. To prepare a BioBrick part from raw DNA, students have to 'stick' specific prefix and suffix short adapters, including restriction enzyme cutting sites, to the desired DNA sequences to make them suitable for the registry and thus, theoretically, standardizable and module ready. The average number of parts submitted 
Table 1 Finalist projects in the iGEM competition, 2006-2013

Team

1 Slovenia 2006

2 Imperial 2006

3 Princeton 2006

4 Peking 2007

5 University of California, Berkeley 2007

6 Paris 2007

7 Ljubljana 2007

8 University of California, San Francisco 2007

9 University of Science and Technology of China 2007

10 Slovenia 2008

11 Freiburg 2008

12 Caltech 2008

13 Cambridge 2009

14 Heidelberg 2009

15 Valencia 2009

16 Slovenia 2010

17 Peking 2010

18 Bristol Cathedral Choir School-Bristol 2010

19 Washington 2011

20 Imperial College 2011

21 Zhejiang University, China 2011

22 Groningen 2012

23 Paris Bettencourt 2012

24 Slovenia 2012

25 Heidelberg 2013

26 Technical University Munich 2013

27 Imperial College 2013

28 Paris Bettencourt 2013

29 Bielefeld 2013

30 Sun Yat-sen University, China 2013
Project

Reference

'Engineered human cells: say NO to sepsis'

'The E.coli reporter'

'Programmed differentiation of mouse embryonic stem cells using artificial signaling pathways'

'Towards self-differentiated bacterial assembly lines'

Bactoblood'

'Synthetic multicellular bacterium'

'Virotrap': a synthetic biology approach against HIV

'Directing biology through synthetic assemblies and organelles'

'Extensible logic circuit in bacteria'

'Immunobricks'

'Modular synthetic receptor system'

'Engineering multi-functional probiotic bacteria'

'E. chromi'

'Spybricks'

'iGEM Lighting Cell Display'

'DNA coding beyond triplets'

'Biodecontamination kit'

'AgrE.coli'

'Make it or break it: diesel production and gluten destruction'

'AuxIn'

'Rainbofilm'

'Food warden' or in any of the project names

'bWARE'

'Switch IT': inducible therapeutics

'The Philosopher's Stone'

'PhyscoFilter'

'Plasticity'

'Fight tuberculosis with modern weapons'

'Ecolectricity'

'iPS cells safeguard' to the registry, around 10 per team, has remained relatively stable throughout the history of the competition, although awardwinning teams tend to submit many more, up to hundreds (Fig. 2a). To date, iGEM teams have collectively submitted $>12,000$ parts to the registry (Fig. 2b). Only around $40 \%$ of those have been checked satisfactorily to ensure that they work as expected upon submission (Fig. 2c). It must be stressed that the growing number of parts, the diversity of assembly methods used and the difficulties of performing quality control on a continuous basis (most of which still relies on the controls made by the teams) require iGEM organizers and the registry to undertake characterization, preparation and delivery work of titanic proportions.

The link between iGEM and the registry also works the other way around: iGEM teams do not only submit parts but are also encouraged to use the BioBrick standards submitted by other teams in previous editions at their convenience, which are already present in the registry. But an analysis of the de novo versus registry-issued parts (according to the case-by-case information in the wiki of each team) reveals that iGEM teams that have been successful in terms of awards tend to avoid the uncertainties of the parts designed and/ or characterized by others and choose to use new, ad hoc DNA parts for a specific purpose (Fig. 2d). As previously mentioned, a cautious attitude toward standard DNA parts seems to be common among participants ${ }^{6,7}$.

In evaluating the success of iGEM as a didactic endeavor, an interesting comparison can be made with similar efforts, such as the FIRST robotics competition (http:// www.usfirst.org/), devoted to promoting engineering and technology skills among young students (most of whom are in high school). Although the number of students trained during the first decade of the FIRST competition is much higher than in iGEM, the latter has reached-with substantially lower overhead costs — an unprecedented geographical spread in a shorter time. Similarly to that of FIRST, the main outcome of iGEM is educational. The main goal of iGEM is to educate students in synthetic biology, so that they might contribute to transformational advances at some time in the future. Funding in iGEM is thus a longterm educational investment. As stressed by Randy Rettberg, general iGEM coordinator and president of the iGEM foundation, during the 2013 closing ceremony, iGEM aims to foster effort, accomplishment, excellence, respect, cooperation and integrity.

From our analysis of iGEM over the past ten years, we believe that the competition has to adapt if it is to maintain its status as a pillar of synthetic biology and as an example of an exciting and dynamic scientific competition. For it to do so, we believe greater focus should be placed on the quality rather than the quantity of parts in the registry. The increasing number of parts 

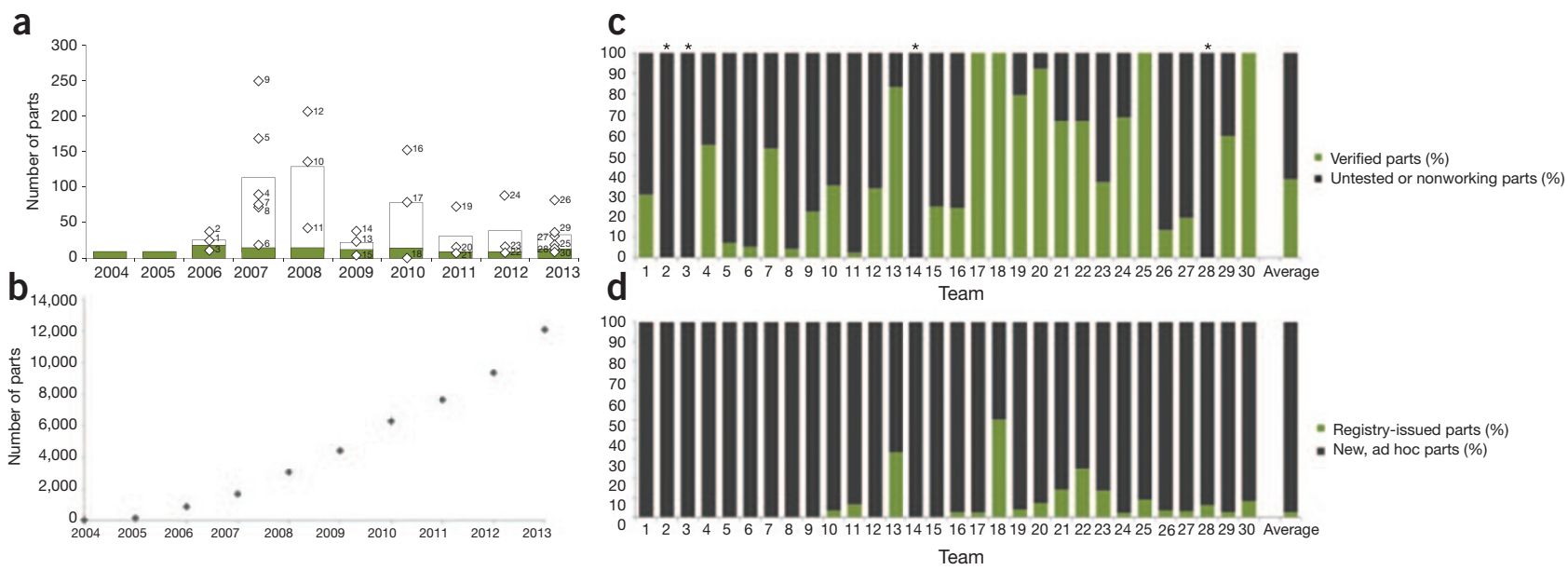

Figure 2 iGEM and the Registry of Standard Biological Parts. (a) Average number of parts submitted per team (green bars) and per finalist team (white bars) during 2004-2013. Diamonds (numbered in accordance with Table 1) represent finalist teams. (b) Cumulative number of iGEM parts in the registry since 2004. (c) Proportions of verified parts (labeled as 'working' in the registry (http://parts. Igem.org/Main_Page)) and untested or nonworking parts submitted to the registry, as stated by iGEM finalist teams in 2006-2013. Finalist teams are numbered according to Table 1. Ambiguous data were found for teams marked with asterisks. (d) Proportion of registry-issued and new parts used by iGEM finalist teams in 2006-2013, as reported on each team's wiki pages.

and the worrying trend of adding new ones rather than using standard ones deserve deep reflection by participants and organizers alike. An intelligent strategy is already in place: iGEM teams get more 'points' if they improve the characterization of an existing part. We would suggest an additional improvement strategy consisting of selecting a relatively small number (no more than 100) of parts every year and asking teams to improve their characterization and/or test their performance in a range of hosts and conditions. This would yield a smaller but improved pool of more reliable parts.

From another perspective, one might ask whether the strong linking of iGEM to the BioBrick biological standard is necessary. Is this the only and/or best standard possible? Should molecular cloning-issued biological devices be a requisite for a team to attend the competition? This question is particularly pertinent in an era where not only adaptor-based standard cloning systems, but also zinc-finger nucleases, transcription activator-like endonucleases and clustered regularly interspaced short palindromic repeats (CRISPR)/Cas-based methods ${ }^{8}$ are playing an increasing part in synthetic biology. In the context of continuously falling costs of DNA chemical synthesis ${ }^{9}$, the cost of chemically synthesizing all the BioBrick parts used by an iGEM team is relatively affordable: considering 1-kilobase constructs (containing a small promoter, an averagelength prokaryotic gene and a terminator) and a low synthesis price (around \$0.28 per base pair), an iGEM team could have ten BioBrick standards ready to transform for $\$ 2,800$. This cost is $\sim 10$ times higher than that of a BioBrick parts assembly kit, but it is still substantially lower than the other expenses an iGEM team must cover (a regional jamboree registration for the whole team, for instance). Furthermore, if molecular cloning were not needed, students would receive presynthesized constructs quickly (in fewer than two weeks), so more time could be dedicated to characterizing the parts in depth. This fact leads us to suggest that, however radical this initiative may be, any synthetic DNA part, even those lacking BioBrick-ready adapters, should be acceptable in the competition.

Regardless of technical developments, iGEM organizers should also reflect on the open-source nature of biological parts, especially if competition projects are to find use in the biotech sector, an area traditionally based on patents and trade secrets. Ownership and sharing in synthetic biology oscillates between widespread gene patenting and open source, in what has been described as a 'diverse ecology'10. iGEM is inspired by engineering and thus by open-source software and distributed innovation. Because the competition focuses on developing particular synthetic biology applications as well as fundamental tools in a scenario of thousands of building parts, open source might be the most logical choice. As Drew Endy stressed in an interview in 2007, "My hope is that by giving things away I will get more back in the long run." One successful example of this philosophy is the BioBrick Public Agreement (BPA) from the BioBricks Foundation, which is a free-to-use "legal tool that allows individuals, companies, and institutions to make their standardized biological parts free for others to use" (http:// biobricks.org/bpa/).

However, a clarification of the registry's legal status is desirable to ensure transparency and ensure that transfer to companies can take place in situations where a project shows applications of particular industrial promise 4 .

Last, we feel that now is an opportune moment for organizers to reevaluate the judging criteria used in iGEM. Judging is more than the final stage of the work; judges' preferences are likely to strongly influence team instructors and advisors and shape their choices for future projects. Given the large diversity of research topics, experimental models and technological choices, awardwinning projects tend to be imitated. A clear example of this is the multiple projects aiming to develop a biodecontamination kit, which are recurrently found among finalists (see Peking 2010 (http://2010.igem.org/ Team:Peking), TU Munich 2013 (http://2013. igem.org/Team:TU-Munich) and Dundee 2013 (http://2013.igem.org/Team:Dundee)). However, although almost all projects have a highly applied purpose, judges are typically pleased by aspects such as the 'originality' of the work (it has not been seen before in iGEM) or its 'roundness' (it tells a story, from a very simple idea to a prototype). One example of this is the Groningen 2012 (http://2012.igem.org/Team:Groningen) project on food spoilage control, which used an original bioprospection strategy to identify and select strong promoter sequences. Beyond the impact this strategy had on the 
judges, the immediate application to industry (or the 'responsible research and innovation' (RRI) issues, which emphasize the utility and benefit for society and the environment) should be key factors of a successful project. If they were, final rankings would certainly change and successful teams would send a clear message on the trends to follow. Judging is always, but particularly in iGEM, a bidirectional process: it ranks proposals but it also shows the way for forthcoming ones.

Given the wide range of complexity and immediate industrial applicability among iGEM projects, we suggest that the degree of sophistication (for example, the number of biological parts/devices used, the difficulty of the host organism and the complexity of regulation output) should be formally considered as a ranking criterion for judges. This would help to further increase the competitiveness of the projects.

If the competition is to place more emphasis on translating projects into real industrial applications, then more thought needs to be put into judging criteria that reinforce this aspect. At present, prizes perhaps encourage spectacular and audacious basic research, which is often not built upon; each year many teams set up brand new projects unrelated to past efforts, even award-winning ones. A greater proportion of industrial members on the judging committee would have an immediate effect by redirecting the competition from the 'game phase' (preliminary exploration) to the 'real-world phase'. More judges from government with expertise in regulatory, health, agricultural or defense issues may also expand the diversity of views and decrease academic biases. An increased presence of Asian judges in the world jamboree would also be highly desirable. Another suggestion for improving the quality of judging is standardization of the number of judges per team. Although similar numbers are assigned to each track, judges can cast votes for unassigned teams. As a result, some teams often have many more votes (either positive or negative) than others. Judging has improved a lot during the past few iGEM competitions. The online questionnaire introduced in 2012 to be filled in by judges incorporates some suggestions that arose during the 2012 regional jamborees, particularly in Europe. It is arguable whether the machine-based ranking of teams should be corrected with data such as team budget or number of students, advisors or instructors. Given the educational nature of the competition, we suggest that it should.
A greater involvement of ELSI specialists and, particularly, a focus on reflexivity and RRI would also help to shape competition trends by encouraging teams to define their projects with societal and environmental benefits as major goals, along with one of the central aspects of RRI: transparency. Transparency has always been a guiding principle in iGEM, with an open-sourcelike Internet-based community that shares data, protocols and DNA samples. The economic resources used in iGEM should not be excluded from such information in future. Detailed data on public and private funding as well as their precise assignment throughout the project should be a requisite for each iGEM team. As stated above, we believe that fair judgment is not possible without taking into account the funding-toresults ratio. Determining this ratio is central to assessing productivity of a particular project and of the competition as a whole. Therefore, for the sake of transparency, we propose that participating teams be asked to make their budget public on their wikis.

In summary, we have proposed a range of suggestions that could improve the quality of standards, increase transparency of funding, foster industrial orientation and redefine and enhance judging of the competition. The experience of a decade of iGEM indicates that such redefinition is imperative for this outstanding competition to meet the great expectations of synthetic biology going forward.

\section{ACKNOWLEDGMENTS}

We are indebted to A. Delgado, V. de Lorenzo and J. Peretó for the critical reading of this manuscript. We are very grateful to anonymously interviewed editors of the top-ranked biotechnology and applied microbiology journals who kindly gave us their opinion on synthetic biology and iGEM. We are indebted to Càtedra de Divulgació de la Ciència (UCC+i) and VLC/Campus-Valencia International Campus of Excellence (Universitat de València) for their enthusiastic support. C.V. was funded with a FPU (Formación de Personal Universitario) grant from the Spanish MECD (Ministerio de Educación, Cultura y Deporte). This work was partially funded by the European Project ST-FLOW (FP7-KBBE-2011-5).

COMPETING FINANCIAL INTERESTS

The authors declare no competing financial interests.

\section{Cristina Vilanova ${ }^{1}$ \& Manuel Porcar ${ }^{1,2}$ \\ ${ }^{1}$ Cavanilles Institute of Biodiversity and Evolutionary Biology (Universitat de València), Valencia, Spain. ${ }^{2}$ Fundació General de la Universitat de València, Valencia, Spain. e-mail:manuel.porcar@uv.es}

1. Endy, D. Nature 438, 449-453 (2005).

2. Goodman, C. Nat. Chem. Biol. 4, 13 (2008).

3. Guan, Z. et al. Bioscience 63, 25-34 (2013).

4. Campos, L. Biosocieties 7, 115-139 (2012).

5. Materi, W. Methods Mol. Biol. 852, 251-272 (2012).

6. Kwok, R. Nature 463, 288-290 (2010).

7. Porcar, M. \& Peretó, J. Syst. Synth. Biol. 6, 79-83 (2012).

8. Gaj, T., Gersbach, C.A. \& Barbas, C.F. Trends Biotechnol. 31, 397-405 (2013).

9. Carlson, R.H. Biology Is Technology (Harvard University Press, 2010).

10. Calvert, J. Biosocieties 7, 169-187 (2012).

11. Sander, C. et al. BMC Syst. Biol. 1, S9 (2007).

12. Lou, C. et al. Mol. Syst. Biol. 6, 350 (2010).

13. Majerle, A., Pristovsek, P., Mancek-Keber, M. \& Jerala, R. J. Biol. Chem. 286, 26228-26237 (2011).

14. Bashor, C.J., Helman, N.C., Yan, S. \& Lim, W.A. Science 319, 1539-1543 (2008).

15. Zhan, J. et al. Mol. Syst. Biol. 6, 388 (2010).

16. Mori, J. et al. Vaccine 30, 5856-5863 (2012).

17. Reis, Y. et al. European Patent Application EP2311961 (2009).

18. Vilanova, C. et al. J. Biotechnol. 152, 93-95 (2011).

19. Conrado, R.J. et al. Nucleic Acids Res. 40, 18791889 (2012).

20. Gordon, S.R. et al. J. Am. Chem. Soc. 134, 20513 20520 (2012).

\section{Sex-ratio-biasing constructs for the control of invasive lower vertebrates}

\section{To the Editor:}

There are few cost-effective means of controlling the many types of invasive fish, amphibians and reptiles that cause substantial economic and ecological damage worldwide ${ }^{1}$. Notable examples include sea lampreys (Petromyzon marinus), common carp (Cyprinus carpio), cane toads (Bufo marinus), bullfrogs (Rana catesbeiana) and the brown tree snake (Boiga irregularis) ${ }^{1}$. Genetic strategies based on constructs that heritably reduce female survival or fertility ${ }^{2-4}$ could provide a solution. Here we report the first successful trials of such constructs in fish and present models suggesting that their use in combination with other strategies could lead to effective species-specific control and possible long-term eradication of such pests.

We examined two approaches to reduce effective female population sizes: femalespecific sterility (FS) and female-specific lethality (FL), focusing on the FL strategy because of the successful application of this approach in insects ${ }^{4}$. A preliminary 